\section{BMJ Global Health}

\title{
'You want to deal with power while riding on power': global perspectives on power in participatory health research and co-production approaches
}

\author{
Beatrice R Egid (D , ${ }^{1}$ María Roura, ${ }^{2}$ Bachera Aktar, ${ }^{3}$ Jessica Amegee Quach, ${ }^{4}$ \\ Ivy Chumo, ${ }^{5}$ Sónia Dias, ${ }^{6}$ Guillermo Hegel, ${ }^{7}$ Laundette Jones, ${ }^{8}$ Robinson Karuga, ${ }^{9}$ \\ Luret Lar, ${ }^{10}$ Yaimie López, ${ }^{1}$ Apurvakumar Pandya, ${ }^{11}$ Theresa C Norton, ${ }^{12}$ \\ Payam Sheikhattari, ${ }^{13}$ Tara Tancred, ${ }^{4}$ Nina Wallerstein, ${ }^{14}$ Emily Zimmerman, ${ }^{15}$ \\ Kim Ozano ${ }^{4}$
}

\begin{abstract}
To cite: Egid BR, Roura $M$, Aktar B, et al. 'You want to deal with power while riding on power': global perspectives on power in participatory health research and co-production approaches. BMJ Global Health 2021;6:e006978. doi:10.1136/ bmjgh-2021-006978
\end{abstract}

Handling editor Stephanie M Topp

Received 22 July 2021 Accepted 23 0ctober 2021
Check for updates

\section{(C) Author(s) (or their} employer(s)) 2021. Re-use permitted under CC BY-NC. No commercial re-use. See rights and permissions. Published by BMJ.

For numbered affiliations see end of article.

\section{Correspondence to} Beatrice R Egid; 194711@Istmed.ac.uk

\section{ABSTRACT}

Introduction Power relations permeate research partnerships and compromise the ability of participatory research approaches to bring about transformational and sustainable change. This study aimed to explore how participatory health researchers engaged in co-production research perceive and experience 'power', and how it is discussed and addressed within the context of research partnerships.

Methods Five online workshops were carried out with participatory health researchers working in different global contexts. Transcripts of the workshops were analysed thematically against the 'Social Ecology of Power' framework and mapped at the micro (individual), meso (interpersonal) or macro (structural) level.

Results A total of 59 participants, with participatory experience in 24 different countries, attended the workshops. At the micro level, key findings included the rarity of explicit discussions on the meaning and impact of power, the use of reflexivity for examining assumptions and power differentials, and the perceived importance of strengthening co-researcher capacity to shift power. At the meso level, participants emphasised the need to manage co-researcher expectations, create spaces for trusted dialogue, and consider the potential risks faced by empowered community partners. Participants were divided over whether gatekeeper engagement aided the research process or acted to exclude marginalised groups from participating. At the macro level, colonial and 'traditional' research legacies were acknowledged to have generated and maintained power inequities within research partnerships.

Conclusions The 'Social Ecology of Power' framework is a useful tool for engaging with power inequities that cut across the social ecology, highlighting how they can operate at the micro, meso and macro level. This study reiterates that power is pervasive, and that while many researchers are intentional about engaging with power, actions and available tools must be used more systematically to identify and address power imbalances in participatory research partnerships, in order to contribute to improved equity and social justice outcomes.

\section{INTRODUCTION}

In recent years, the participatory health research (PHR) paradigm, a co-production research process, has gained considerable traction as governments and research councils in many countries move to increase participation of citizens in applied health research. ${ }^{12}$ In PHR, researchers in universities and other institutions aim to work in equal partnership with non-academic stakeholders including patients, caregivers, clinicians, policy-makers, health system leaders and supporting organisations to design and conduct research, and to translate, disseminate and implement research findings. ${ }^{3}$ In this paper, we use the term 'co-researchers' to refer to non-academic stakeholders who are colleagues and equal partners in the research process. In addition, we refer to 'community' as a group of individuals who have a particular characteristic or interest in common, which could be the place that they live, an aspect of their identity (eg, sexuality, disability), their profession or their use of a particular service. ${ }^{4}$

PHR strives to level power relations between academic researchers and co-researchers, whereby co-researchers become equal partners in the process rather than 'subjects' or 'participants'. ${ }^{5}$ There are, however, increasing and well-founded concerns that participation in PHR projects is often a superficial 'tick box' process in which unequal power relations remain unaddressed, compromising the potential of participatory processes to achieve greater equity and justice. ${ }^{6-8}$ For example, genuine redistribution of power can be severely limited by 'functional participation', where the unwillingness of researchers to 


\section{Key questions}

\section{What is already known?}

- Power imbalances within research partnerships compromise the ability of participatory research approaches to bring about positive and sustainable change.

- Contemporary knowledge systems on power are dominated by Western authors and modes of thinking, particularly in the field of global health.

\section{What are the new findings?}

- The 'Social Ecology of Power' framework can be used to explore qualitative data on participatory health researchers' perceptions and experiences of power, illuminating the ways that power operates at the micro, meso and macro level.

- While researcher assumptions and the abstract nature of 'power' act to limit explicit discussion of the concept, reflexivity and awareness of positionality can help to examine and address power differentials in research partnerships.

- In striving to empower individuals and communities, participatory research exposes different safeguarding risks compared with 'traditional' research approaches.

- Some participatory health researchers view gatekeeper engagement as beneficial and essential to the research process, while others are concerned that gatekeepers can limit access to marginalised groups.

\section{What do the new findings imply?}

- Frameworks, activities and tools to support research partnerships to discuss and address power imbalances must be used more systematically to improve equity and social justice outcomes.

- The ethical risks of empowerment in participatory research should be examined more closely, including further consideration of how sociopolitical contexts vary in the extent to which they support individual and community empowerment.

- Researchers should be mindful when using gatekeepers to identify partners for co-production research, particularly when attempting to engage with marginalised groups.

relinquish decision-making power ${ }^{9}$ and to view community knowledge as equal to academic knowledge ${ }^{10}$ leaves major decisions being made by research institutions, while co-researchers are confined to supportive and advisory roles. ${ }^{11}$ There is also an oversimplified expectation in participatory research that trust can be built on underlying hierarchies of power. ${ }^{12}$ Throughout history, there have been numerous cases of unethical research misconduct as a result of unequal power relations, exemplified by the infamous Tuskegee Syphilis Study ${ }^{13}$; Native Americans' participation in research leading to stereotypes about their elevated alcohol consumption ${ }^{14}$; and research studies that mainly portrayed the HIV/AIDS problem as associated with homosexuality, resulting in new and enhanced stigma attached to both having HIV/ AIDS and being homosexual. ${ }^{15}$ Examples such as these have created a legacy of mistrust between researchers and the researched communities, and yet (Western) academic researchers who embody, historically, a hugely disproportionate amount of power, frequently carry out
PHR in communities in which they are outsiders and where those power imbalances persist. ${ }^{16}$

The concept of 'power' has been discussed and critiqued extensively in relation to participatory research. ${ }^{17-20}$ Structural imbalances of power within community-based participatory research (CBPR) have been directly explored within the context of equity and policy goals, ${ }^{21-23}$ while cross-site CBPR case studies have also enunciated the importance of both structural and relational power. ${ }^{19} 20$ This systemic understanding of power resonates with socioecological approaches, which situate individual behaviours within broader interpersonal dynamics and societal structures. With an explicit attention to the interdependence across different domains, socioecological frameworks allow us to examine how power dynamics operate within and across the individual (micro), interpersonal (meso), and structural levels (macro).$^{24}$ A recently developed conceptual framework has explicitly situated power inequities within a wider system of bidirectional interconnections operating within and across these three levels in PHR. ${ }^{6}$ This 'Social Ecology of Power' conceptual framework specifically accounts for the way in which power dynamics filter throughout the different layers of the social ecology and provides us with a tool to examine how power inequities cut across the macro level, meso level and micro level in PHR. Still, power remains an elusive concept to define.

According to Gaventa and Cornwall, ${ }^{25}$ power within PHR can be exercised as either exclusionary or inclusionary, taking place within multiple contexts including the historical relationships between academic institutions and community stakeholders, the dominance of Western and medical research from highly developed nations and the hierarchical power structures and relationships within each national or local context. They identify how 'power over' others can be direct or hidden; directly, through decision-making structures that favour academics within research or in contexts where regimes are more authoritarian than democratic, or covertly, when community partners are fearful of even raising issues or perceiving that they won't be heard when they do. ${ }^{26}$ In contrast to the role of 'power over' that prevents authentic partnering, theories of power also recognise 'power to' act, when people have the capacity of human agency to work towards change. PHR partnerships offer the opportunity to change the dynamics and strengthen co-researcher capacities, both within the co-production process and in their targets of change. ${ }^{27}$

However, few studies have utilised qualitative methods to investigate experiences and perceptions of power, ${ }^{28-30}$ and there is a clear gap in understanding of how participatory health researchers perceive and address power imbalances in their projects, and more widely in the current global health research landscape. Furthermore, contemporary knowledge systems on power are dominated by Western authors and modes of thinking, ${ }^{31} 32$ evidenced by a recent study found that most co-production of health research has been conducted in highly 
developed settings, with less than $2 \%$ of co-production literature examining low- and middle-income countries (LMICs). ${ }^{2}$ Engaging with perspectives of participatory health researchers-particularly those from the Global South-and considering how experiences vary across countries, disciplines and income contexts, will help to produce more nuanced understandings of power in realworld settings, providing a platform for voices that are often missing from the research scholarship on power. The qualitative data generated from exploration of these perspectives can be used to develop concrete actions to address power inequities in PHR partnerships, and to validate the 'Social Ecology of Power' framework described above, which at present draws only from peer reviewed literature and the experiential knowledge of it's author.

Drawing from the 'Social Ecology of Power' framework, this qualitative study aimed to explore how participatory health researchers from a variety of global contexts perceive 'power', and how this concept is discussed within the context of specific research partnerships. It also sought to identify how imbalances of power are addressed within research partnerships, and what is done to promote or facilitate power sharing, participation in research, and community empowerment. Furthermore, a primary intention of this work was to provide a space for knowledge sharing and reciprocal learning between participatory health researchers on the subject of power. As such, we refer to the qualitative data collection technique used in this study as 'workshop' rather than 'focus group discussion', reflecting the different forms of participation available to participants, the participant-directed flow of conversation, and the reciprocal learning that took place. ${ }^{33} 34$

\section{METHODS}

Detailed study methods and description of research project positionality can be found in Egid et al 2021, ${ }^{34}$ including the authors' reflexivity regarding workshop conduct and power dynamics within the research process.

\section{Sampling and recruitment}

We recruited participatory health researchers-defined here as people with experience working on projects aligned with participatory principles, including PHR, CBPR and Participatory Action Research, or having used participatory methods - to take part in the online workshops. An advert for the workshops was circulated via social media/twitter and direct email, and through institutional programme websites. Participant recruitment was thereby through self-selection, followed by snowball sampling, ${ }^{35}$ as detailed in Egid et al $2021^{34}$. Participants were issued with participant information sheets and signed consent forms.

Although we initially intended to recruit only people with direct experience of participatory research, we were contacted by several graduate students and academic researchers interested in or planning to conduct participatory research projects for the first time. We supported their attendance and engagement in the workshops, reflecting the principal focus on knowledge sharing and mutual learning between participants.

\section{Data collection}

The workshops were semi-structured and guided by key questions based on the following themes: (1) defining and discussing power, (2) addressing power relations and empowerment, (3) measuring and evaluating power. Workshops were conducted online (in GoToMeeting/ Zoom) and each facilitated by two authors, with support from a third author on WhatsApp. In the workshops, facilitators gave an introductory presentation on the objectives of the study, terminology to be used and process of the workshop, then displayed questions on a shared screen and posed them to the group. Participants were able to respond and contribute to the discussion verbally or by using the 'chat box'.

The first workshop (Workshop 1) was a small-scale pilot, while the other four workshops were larger and loosely based on region for example, Workshop 2 was focused on experiences in Asia, Workshop 3 on Africa, Workshop 4 on Europe and Workshop 5 on Latin America. Workshop discussions lasted between 1 hour $35 \mathrm{~min}$ and 2 hours and were video recorded and transcribed verbatim. Workshop 5 was conducted in Spanish and translated into English, while all other workshops were conducted in English.

\section{Analysis}

Framework analysis was used to analyse the transcripts. ${ }^{36}$ Codes were developed deductively from the 'Social Ecology of Power' framework. ${ }^{6}$ NVivo V.12 software was used to code and organise the data. After familiarisation with the transcripts, an initial coding framework was developed and refined through discussion with facilitators and then applied to all the transcripts and chat box data. A charting process was used to identify overarching themes which were synthesised and organised around the framework headings, and are presented in the Results section. We also adapted several of the subtheme titles from those presented in the framework, in order to reflect our findings more accurately. For the purposes of this study, we have presented themes at the level (micro, meso or macro) where we believe they fit most harmoniously, whilst acknowledging that they could have been situated elsewhere.

\section{RESULTS}

\section{Participants}

Five workshops were conducted between 6 May and 9 June 2020, with a total of 59 participants. Each workshop was composed of between 9 and 17 participants, and participants characteristics are displayed in table 1. Most participants were from academic or research institutes $(69 \%)$, while $20 \%$ worked with non-governmental organisations (NGOs) or other private organisations, and 7\% were from health systems-none of the participants were 


\begin{tabular}{|c|c|c|c|c|c|}
\hline & $\begin{array}{l}\text { Workshop } 1 \\
(n=6)\end{array}$ & $\begin{array}{l}\text { Workshop } 2 \\
(n=14)\end{array}$ & $\begin{array}{l}\text { Workshop } 3 \\
(n=13)\end{array}$ & $\begin{array}{l}\text { Workshop } 4 \\
(n=17)\end{array}$ & $\begin{array}{l}\text { Workshop } 5 \\
(n=9)\end{array}$ \\
\hline \multicolumn{6}{|l|}{ Type of partner } \\
\hline Academy/research institute & 1 & 11 & 8 & 14 & 7 \\
\hline NGO & 3 & 3 & 5 & 1 & 0 \\
\hline Health system & 1 & 0 & 0 & 1 & 2 \\
\hline Not specified & 1 & 0 & 0 & 1 & 0 \\
\hline Countries of project experience & $\begin{array}{l}\text { Liberia, } \\
\text { Nigeria, } \\
\text { Cameroon }\end{array}$ & $\begin{array}{l}\text { Bangladesh, } \\
\text { Nigeria, Vietnam, } \\
\text { India, USA }\end{array}$ & $\begin{array}{l}\text { Nigeria, India, } \\
\text { Kenya, Philippines, } \\
\text { Sierra Leone, } \\
\text { Zambia, Uganda, } \\
\text { Tanzania }\end{array}$ & $\begin{array}{l}\text { Liberia, Sierra } \\
\text { Leone, Nigeria, } \\
\text { Kenya, Bangladesh, } \\
\text { Ghana, Malawi, } \\
\text { Uganda, USA, } \\
\text { UK, Cameroon, } \\
\text { Germany, India, } \\
\text { Sweden, Nepal }\end{array}$ & $\begin{array}{l}\text { Guatemala, Costa } \\
\text { Rica, Colombia, } \\
\text { Brazil, Panama }\end{array}$ \\
\hline
\end{tabular}

directly from partnered 'communities'. Participants had experience working across 24 different countries.

\section{Power at the micro level: individual values and attitudes Assumptions about power}

Most participants reported that the concept of 'power' was rarely explicitly discussed in their partnerships, and only a few participants knew of or had used specific definitions of the term. Some participants assumed that the co-researchers in their partnerships already understood the meaning and implications of power and therefore did not see a need for discussion (table 2, Q1). Others believed that adopting a participatory approach was sufficient to address power inequities, negating the need to actively discuss power. The multiple dimensions, abstract nature and intangibility of power as a concept also posed a major barrier to its discussion and definition within partnerships (table 2, Q2). As a result of this conceptual complexity, some participants perceived that their co-researchers lacked interest in discussing power (table 2, Q3). To address this, participants generally avoid using jargon in discussion with co-researchers, instead using metaphor and alternative explanations to help demystify complex concepts and establish mutual understanding of issues (table 2, Q4).

\section{Positionality and reflexivity}

Many participants spoke about the influence that researcher and co-researcher positionality can have on how power is experienced and understood (table 2, Q5). Participants described how researcher positionality can interact with power hierarchies, such as those surrounding race (table 2 , Q6) and gender. Workshop participants discussed how positionality can help to determine which members of the research team are best suited to carry out particular roles in projects. For example, in many cases co-researchers from a community of study were thought to be better placed to collect data and facilitate sessions with community members, helping to negate the typically unequal power dynamic between academic researchers and community members and to create a more relaxed sharing environment (table 2, Q7).

Reflexivity was discussed across all workshops as a means for researchers to engage in critical dialogue about their positionalities in terms of privilege and power, and to consider how this positionality influences their work with co-researchers (table 2, Q8). Some participants believed that being reflexive enabled them to better identify and address power imbalances in their partnerships. A few participants communicated that they had encouraged co-researchers to engage in reflexivity sessions as well, often in the form of reflexive group discussions, which were thought to be useful for identifying opportunities for improvement and change (table 2, Q9).

\section{Individual capacity strengthening}

Participants discussed how capacity strengthening was a central aim of participatory research, which could aid in the empowerment of co-researchers. Bilateral training and knowledge exchange (between co-researchers and academic researchers) in different forms was seen as an important opportunity for this, helping to build confidence in co-researchers and increase their sense of ownership of projects and ultimate project impact (table 2, Q10). Increasing co-researchers' access to information also helped to strengthen capacity and formed an important aspect of community empowerment. Open-source educational materials were noted as a potential means to aid accessibility, as was sharing information in clear formats. Participants also highlighted the importance of mutual learning between researchers and co-researchers, which helps to maximise researcher understanding of a topic in the local context (table 2, Q11).

\section{Power at the meso level: intersectoral spaces and multistakeholder teams \\ Project governance}

Most participants stated that research teams and stakeholders met regularly throughout the research process, 
Table 2 Power dynamics operating at the micro (individual) level

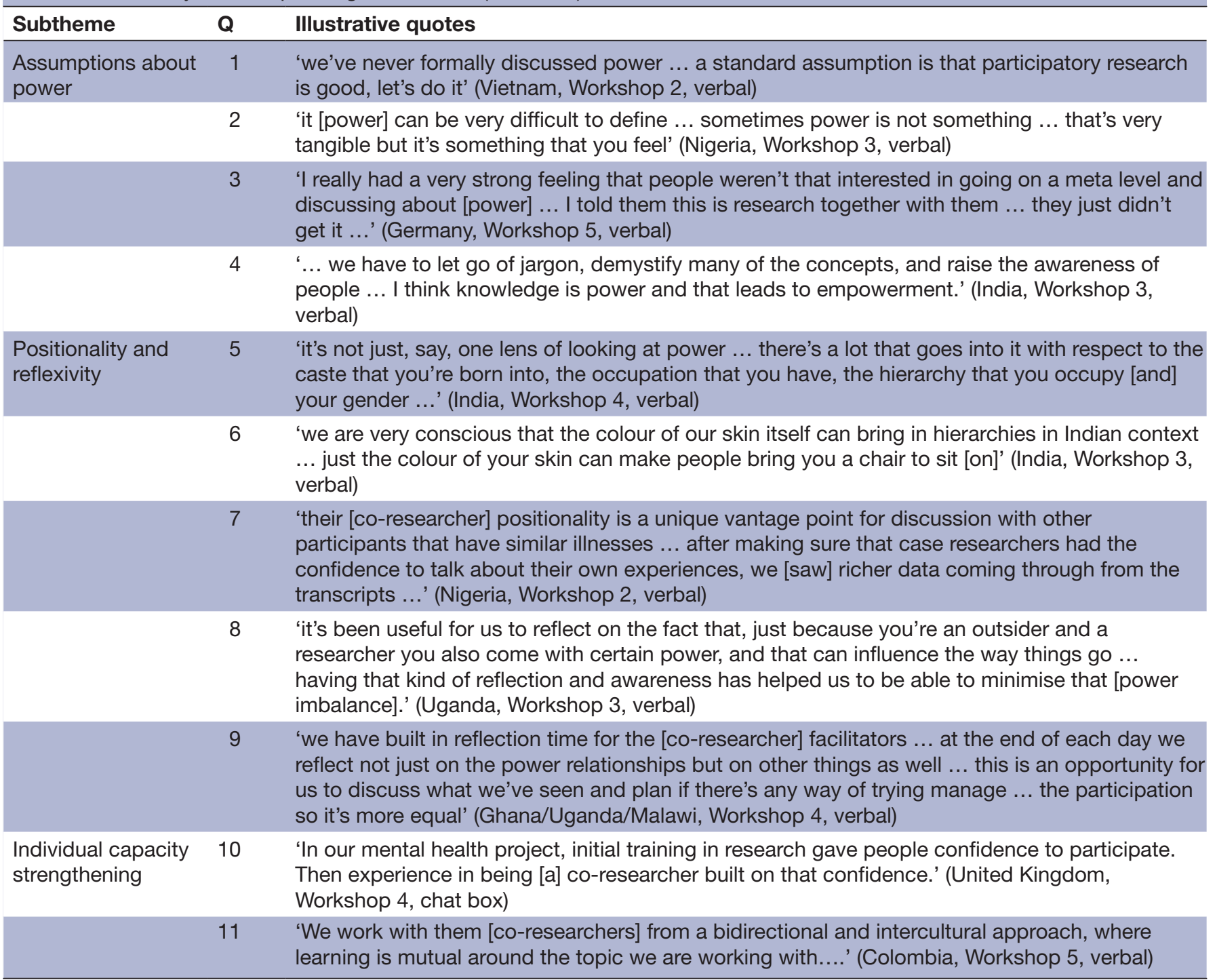

providing space for direct communication between researchers and co-researchers and helping to ensure that all partners remain aligned in their understanding of the project scope (table 3, Q1). Participants discussed how co-researchers can feel let down by academic researchers, particularly when they express opinions or seek change and nothing happens, and how managing expectations can play an important role in building trust and avoiding disagreements. They suggested using ranking exercises to understand community priorities and developing terms of reference to manage expectations (table 3, Q2).

Participants spoke about how they tried to support shifts in power over time through transformational leadership within their partnerships, and within existing organisations such as health systems. One of the strategies for doing this was to strengthen the capacity of co-researchers to become peer educators/trainers within their own communities, so they could work with communities and leaders to drive action without academic partners. Skills training included political advocacy, developing and communicating action plans, and constructing cases for additional funding or resources, all of which contribute to the sustainability of positive change in the community beyond the scope of a particular research project. According to participants, knowledge sharing also helped to redistribute power, enabling co-researchers to share knowledge they gain with other community partners to facilitate informed and autonomous decision-making and to increase awareness of community partners' rights and influence within projects (table 3, Q3). Other strategies to shift power included handing over decisionmaking responsibilities to co-researchers, assessing who makes the decisions, motivating co-researchers to take ownership and establishing structures that promote leadership in moving actions forward independently of the research team (table 3, Q4).

Participants emphasised how their projects were committed to sharing power and engaging co-researchers at every stage of the research process, from conception to dissemination. For example, in the planning stages, 
Table 3 Power dynamics operating at the meso (interpersonal) level

\begin{tabular}{lll}
\hline Subtheme & $\mathbf{Q}$ & Illustrative quote \\
\hline Project governance & 1 & $\begin{array}{l}\text { 'diverse population blocs such as youths, women, migrant groups etc express their preferences } \\
\text { through direct engagement with researchers rather than through any go- between. This presents } \\
\text { voice that are often lost in top- bottom approaches.' (Nigeria, Workshop 3, chat box) }\end{array}$
\end{tabular}

2 'transparency is really key ... not everything will be feasible and that could be due to project reasons, due to the project timelines ... [we] made sure that everyone had space to rank what priorities they had, so we tried to make it as participatory as possible, but of course there will be disappointment ...' (Nigeria, Workshop 2, verbal)

3 'we work in excluded communities, historically excluded, like indigenous [communities] ... people that haven't had access to education, people that do not have health services. They don't even have a notion of rights, their own rights. We tell them 'look, you have to use your rights.' 'What rights?' (Guatemala, Workshop 5, verbal)

4 'we empower the .... teams so that they can think outside the box, they can make their decisions and not just look at what the headquarters do...' (Malawi, Workshop 4, verbal)

5 'we [academic researchers] put in some tentative interventions that we could do, but mentioned that we will collaborate with the stakeholders at community level to build this further, in terms of asking them what they would like to be done, where does the community want this [the HIV testing station] to be put, who do they want to manage or distribute the HIV self-testing kits ...' (Zambia, Workshop 3, verbal)

6 'we have stakeholder meetings where we have our dissemination ... we make sure that ... community health workers, people affected by NTDs [and] all the co-researchers are involved in that, including NTD implementers ... the strategy ... is inclusion, making sure everyone has a place at the table' (Nigeria, Workshop 2, verbal)

7 'Build with community actors in their own territory, in their contexts, starting by recognizing that external researchers there are ignorant, foreign and in need of knowledge.' (Colombia, Workshop 5 , chat box)

8 'In a lot of instances, people were 'volun-told' to participate, and it was tough to navigate a way to avoid this scenario!' (Tanzania/Uganda, Workshop 3, chat box)

9 'with regards to consulting with the community to inform the design of interventions, I feel like we can run the risk of falling into the trap of calling it participatory research when in fact all we're doing is using these community partners as informants ...' (Philippines/Kenya/Uganda/Nigeria, Workshop 3, verbal)

10 'when you don't promote these positive behaviours, and you don't shift power, usually you find that after the intervention is done... there is no empowerment that took place ... the power was still with the researchers' (Zambia, Workshop 3, verbal)

\begin{tabular}{|c|c|c|}
\hline \multirow[t]{3}{*}{$\begin{array}{l}\text { Effective techniques } \\
\text { for dialogue }\end{array}$} & 11 & $\begin{array}{l}\text { 'I always thought power sharing is something about giving power away ... but it's also about } \\
\text { offering a safe room or a space where power can be shared ... it gives them [co-researchers] the } \\
\text { chance to develop their participation in different ways.' (Germany, Workshop 4, verbal) }\end{array}$ \\
\hline & 12 & $\begin{array}{l}\text { ' } \ldots \text { if people are more used to sitting under a tree to have a chat while sharing a coffee, then we } \\
\text { should do that instead of taking them to a hotel or a restaurant' (Guatemala, Workshop } 5 \text {, verbal) }\end{array}$ \\
\hline & 13 & $\begin{array}{l}\text { 'difficulties in the internal dynamics [in the research team] ... [are] reflected in the relationship } \\
\text { established with the communities ... if we don't make an introspection ... not [as] individuals } \\
\text { but to the whole team ... how we work, which roles we assume, how we exchange and share } \\
\text { knowledge ... [it] will affect the results and the processes with the communities.' (Colombia, } \\
\text { Workshop 5, verbal) }\end{array}$ \\
\hline \multirow[t]{3}{*}{$\begin{array}{l}\text { Associational } \\
\text { landscape and } \\
\text { representation }\end{array}$} & 14 & $\begin{array}{l}\text { 'power relationships always exist between the academic and non-academic, between university } \\
\text { and non-university, between city and village, between indigenous and non-indigenous ... Even } \\
\text { within the community itself, there are socio-economic scales, gender issues ...' (Guatemala, } \\
\text { Workshop 5, verbal) }\end{array}$ \\
\hline & 15 & $\begin{array}{l}\text { 'we talk to community partners and we try to identify who are actually the ones who are the } \\
\text { most marginalised... we wanted to ensure that we give them an opportunity to participate in our } \\
\text { process.' (Bangladesh, Workshop 2, verbal) }\end{array}$ \\
\hline & 16 & $\begin{array}{l}\text { 'an [existing community] structure that is always set and knows what is happening in those } \\
\text { communities ... [can] lead you as a researcher through these communities for whatever } \\
\text { information you may want...' (Sierra Leone, Workshop 3, verbal) }\end{array}$ \\
\hline
\end{tabular}


Table 3 Continued

\begin{tabular}{lll}
\hline Subtheme & $\mathbf{Q}$ & Illustrative quote \\
\hline 17 & $\begin{array}{l}\text { '... they [unions] are quite politically influenced and l'm just afraid that by having them as the } \\
\text { main partners, the gatekeepers, they might just silence the people we actually want to engage, } \\
\text { the people who are less likely to speak up and take actions for their own communities.' (Vietnam, } \\
\text { Workshop 2, verbal) }\end{array}$
\end{tabular}

18 'you want to deal with power while riding on power, and I don't know how much equity that brings ... you want to identify the gatekeepers ... someone who can influence ... do we actually get to the point where we are able to bring in equity, or do we just empower the already empowered in the community? ... it seems that we don't actually really reach the people who need it most.' (Zambia, Workshop 3, verbal)

19 'It is a tightrope walk. We need their [local leaders'] consent to the research. Yet their power could also silence voices in the community.' (Kenya, Workshop 3, chat box)

20 '... ignoring these [gatekeeping] structures is also a problem because these people can demolish the process of new leaderships ... [so] we involve the people with this profile in activities and give them a symbolic role ... but if you ignore these traditional power structures, you infringe the leadership efforts we are trying to raise.' (Guatemala, Workshop 5, verbal)

\begin{tabular}{|c|c|c|}
\hline \multirow[t]{4}{*}{$\begin{array}{l}\text { Reward systems } \\
\text { and potential risks }\end{array}$} & 21 & $\begin{array}{l}\text { '[they want] a vest saying 'Community Sponsor for Health Rights', with a logo that they design } \\
\text { for their network of community sponsors ... this empowers them ... [they want something] that } \\
\text { allows them to gain recognition and prestige in their community ...' (Guatemala, Workshop 5, } \\
\text { verbal) }\end{array}$ \\
\hline & 22 & $\begin{array}{l}\text { 'Taking part in the research gave people a passion about what they wanted to change and felt } \\
\text { strongly about working towards a sense of justice.' (United Kingdom, Workshop 4, chat box) }\end{array}$ \\
\hline & 23 & $\begin{array}{l}\text { '... we may leave the project, [and] the [empowered] person is left alone and then they are killed, } \\
\text { or there are retaliations, and they need support and then we think that it's not our responsibility } \\
\ldots \text { 'good luck, you're alone leading your community'. This is not fair, right?' (Guatemala, } \\
\text { Workshop 5, verbal) }\end{array}$ \\
\hline & 24 & $\begin{array}{l}\text { '... we need to look for local alliances, [to] find ways that our leaders can have higher recognition } \\
\text { and visibility at community level [and] receive respect ... [to] reduce the possibility of attacks, } \\
\text { discrimination, retaliations ... if only the farmer is empowered, they are badly treated at every } \\
\text { institution they visit .... [we need to] build favourable contexts for community empowerment and } \\
\text { leadership.' (Guatemala, Workshop } 5 \text {, verbal) }\end{array}$ \\
\hline
\end{tabular}

participants felt that ensuring co-researcher involvement was necessary for instilling a sense of community ownership over the research and ensuring that the research genuinely addressed the needs of the community. One participant described how while academic researchers might present potential approaches for the research at the planning stage, co-researchers should decide if, how and when those approaches should be adopted (table 3, Q5). At the dissemination stage of the research, participants encouraged co-researchers to decide how they wanted the research outputs to be shared, endorsing opportunities for co-researchers to share and discuss the research with their communities and with wider stakeholder groups (table 3, Q6).

Many participants discussed the importance of respecting, acknowledging the relevance of, and utilising community knowledge, which can aid in the development of shared expertise and goals between partners. Participants agreed that co-researchers should be viewed as the experts on their own context, and that their valuable local knowledge and deep understanding of community needs should be recognised and used in the co-production process (table $3, Q 7$ ). Participants also discussed the importance of documentation for preserving community knowledge, safeguarding intellectual contributions and preventing exploitation.

Participants discussed how unequal power dynamics can lead to the imposition of participation on community members. They described how academic researchers in positions of power can consciously or unconsciously pressure community members into participating in research which they do not want to be part of (table $3, \mathrm{Q} 8$ ). Others discussed how community participation in research can sometimes be 'tokenistic', whereby community involvement only goes as far as informing or providing data for academic researchers, reflecting a lack of real commitment to shared decision-making (table 3, Q9). One participant described how this tokenistic participation and failure to shift power is evidenced when little or no change is observed at the end of the research process (table 3, Q10).

\section{Effective techniques for dialogue}

Across all workshops, participants emphasised the importance of creating safe spaces for dialogue, where co-researchers can contribute freely and participate in the research process however they feel comfortable (table 3, Q11). Conducting research activities and discussions in settings that were familiar to the co-researchers, rather 
than in locations more convenient for the researcher, was deemed crucial (table 3, Q12). Several participants described conducting sessions specifically for co-researchers from particular marginalised groups, meaning that all participants would have some shared experience and feel more comfortable in participating. Outside of these dedicated sessions, participants described how it can be helpful to ensure that there are at least two representatives from each marginalised group, to encourage participation and to balance out the group dynamics. The setting of ground rules to ensure all opinions were respected, and encouraging the use of participatory methods, including creative and narrative methods, were also mentioned as ways to create safe spaces for participation. Participants mentioned how monitoring power dynamics and the relational environment within academic research teams can help to ensure that internal issues do not negatively impact relationships with communities (table 3, Q13).

\section{Associational landscape and representation}

While participants frequently discussed power hierarchies between academic researchers and community co-researchers, there was a keen awareness of the power imbalances which exist between other stakeholder groups and within community groups themselves (table 3, Q14). Within communities, participants described how the voices and contributions of people from marginalised groups are often overshadowed by those from dominant groups, or by those who have direct relationships with community leaders. Workshop participants referenced people with disabilities, migrants, women, indigenous people, elderly people and adolescents as groups that hold less power but stand to gain from power redistribution. Some participants described a process of dialogue with community members for identifying the most marginalised groups within communities (table 3, Q15).

One subject that divided opinion among workshop participants was the extent to which participatory research projects should engage with existing power structures in communities. To many participants, engaging local leaders or other influential people in the community was deemed essential for community access and the buy-in of the community members (table 3, Q16). Other participants expressed concern that 'gatekeepers,' such as local NGOs, state-sponsored organisations, and community leaders can sometimes act to silence community voices, particularly those of excluded community members, which can lead to further marginalisation. Meanwhile, community members in relative positions of power may be the ones who reap the benefits of the research, which reinforces existing power imbalances (table 3, Q17-18). One participant succinctly summarised this dilemma of engaging with gatekeepers (table 3, Q19). While few solutions to this issue were offered, some participants suggested that gatekeepers could be engaged symbolically while participation and leadership opportunities were directed towards less powerful community members (table 3, Q20).

\section{Reward systems and potential risks}

Co-researcher compensation for participation was discussed by several participants, as was the role of incentivisation in encouraging people to participate or take on leadership roles. Participants described how while economic incentives were often used, they were not necessarily appropriate, and that sometimes community partners preferred compensation in the form of recognition and prestige in their community, achieving social justice or learning new skills (table 3, Q21-22).

While individual and community empowerment was agreed to be an aim of participatory research, some workshop participants were wary of the potential risks associated with 'becoming empowered' and discussed the ethical responsibility of academic researchers in considering this risk (table 3, Q23). They emphasised the importance of understanding the wider societal context in which participatory research takes place and attempting to create environments that are supportive of empowerment (table 3, Q24).

\section{Power at the macro level: sociopolitical structures} Historical and economic factors

Participants were aware of how certain power hierarchies are very deeply entrenched in societies, such as those surrounding race and the legacy of colonisation. Participants acknowledged that these longstanding inequalities are often challenging to navigate and address (table 4, Q1). Furthermore, participants described how communities can become so used to 'traditional' research approaches-where external researchers make decisions and implement interventions without consulting or engaging communities-that communities may lack confidence and trust in 'new' participatory research approaches (table 4, Q2).

\section{Distribution of power and resources}

Participants described how power imbalances could lead to differential access to resources such as education, information, and healthcare provision within communities, with marginalised groups often excluded or overlooked during resource distribution (table 4, Q3). This uneven distribution was thought to affect the ability of marginalised groups to participate in research.

\section{DISCUSSION}

Across five international workshops, participants in this study described their experiences and understandings of how power influences-and operates within-PHR partnerships. We mapped the themes which arose in the analysis onto the 'Social Ecology of Power' framework, locating themes at the individual (micro), interpersonal (meso) or structural (macro) level. This framework accounts for the way in which power dynamics filter across and within the social ecology, highlighting the 
Table 4 Power dynamics operating at the macro (structural) level

\begin{tabular}{|c|c|c|}
\hline Subtheme & $\mathbf{Q}$ & Illustrative quote \\
\hline \multirow[t]{2}{*}{$\begin{array}{l}\text { Historical and economic } \\
\text { factors }\end{array}$} & 1 & $\begin{array}{l}\text { 'in a lot of contexts there's [a] deep rooted power dynamic as a result of colonisation .... } \\
\text { fragility [or] conflict ... there's a lot of things that you have to acknowledge that you'll never } \\
\text { be able to ... manage ... or remove' (Liberia/Sierra Leone/Nigeria, Workshop } 4 \text {, verbal) }\end{array}$ \\
\hline & 2 & $\begin{array}{l}\text { 'the concept of participatory action research is ... new to a lot of communities ... they } \\
\text { really struggle to understand that they actually have the power to make a difference ... } \\
\text { they're more used to researchers just coming in and dictating what needs to be done.' } \\
\text { (India, Workshop 3, verbal) }\end{array}$ \\
\hline $\begin{array}{l}\text { Distribution of power and } \\
\text { resources }\end{array}$ & 3 & $\begin{array}{l}\text { 'marginalised groups like people with disabilities, migrants, and foreigners in the } \\
\text { community [sometimes miss out] ... there's a community in one of the states [where] } \\
\text { medicines have been [distributed] for about fiveyears, but during the research [we] } \\
\text { discovered that such people were not being given medicine ...' (Nigeria, Workshop 2, } \\
\text { verbal) }\end{array}$ \\
\hline
\end{tabular}

bidirectional interconnections between the different levels ${ }^{6}$ - it was therefore a useful tool for examining power in participatory research and encouraged us to consider the interconnectivity, fluidity and granularity of power.

In this section, we discuss the key study findings at each socioecological level in relation to existing theory and literature, and present a table of practical actions and tools that could be used to address power inequities in PHR partnerships and beyond (table 5).

\section{Micro level}

At the micro level, key findings included rarity of explicit discussions on the meaning and impact of power, the use of reflexivity for examining assumptions and power differentials, the importance of demystifying concepts around power, and the strengthening of co-researcher capacity to encourage them to pursue co-produced knowledge and ensure sustainable impact on research aspirations and beyond.

Considering the significant literature on the importance of embedding and addressing power in PHR, ${ }^{6} 1937$ reports that power was rarely discussed in the research partnerships represented was surprising and implies that exploring and addressing power is likely still a common practice gap. This finding has also been mirrored in other studies. A systematic review of community participation in health systems interventions in LMICs found that few peer-reviewed journal articles even mention power or control, and that such research is largely under theorised. ${ }^{38}$ Participants here expressed a lack of prioritisation by co-researchers for understanding and addressing power dynamics directly, stating the need to focus on 'more important' or 'worrying' concerns. By demystifying terms like power and empowerment and exploring reflexivity and positionality, it is likely that research partners would be able to comprehend the value of understanding power and the impact that power structures at multiple levels have on other societal inequities and in relation to other priorities. Without providing a space to define, redefine and conceptualise these power forces, projects may be less likely to adhere to the principles of
PHR, especially in relation to addressing critical factors (eg, race, gender, ethnicity, racism, disability, patriarchy and social class) that can influence the attainment of equitable, trusting research partnerships. ${ }^{22} 39$

Facilitating collaborative, equitable partnerships in all research phases involves an empowering and powersharing process that attends to social inequalities. Thus, without understanding power conceptually and in relation to wider social, political, historical factors that influence social outcomes, such inequalities can remain hidden and have the potential to reinforce imbalances in power within the partnership and beyond. As found in previous studies where power issues are not identified and discussed within the research partnership, unequal power dynamics persist and can result in non-reflexive claims to equity. ${ }^{40}$ These claims can perpetuate the exclusion of dissenting voices and the most vulnerable individuals and communities, especially in contexts where such views would challenge the 'status quo' and the allocation of privileges that comes with it.

In terms of strengthening capacity, participants emphasised the importance of facilitating opportunities for co-researchers to develop knowledge and skills through training, which can in turn increase their confidence and access to opportunities. Furthermore, when community co-researchers gain the confidence to share their life experiences, they can become situated as insider researchers and are able to collect and represent community voices, contributing to the power sharing process. Skills like these have intrinsic value; they contribute to social empowerment, creating a sense of personal and collective purpose and catalysing communities to use co-produced knowledge and take action that can help sustain impact beyond individual research projects. ${ }^{29} 42$ In addition, mutual learning helps ensure that researchers learn from co-researchers about the project topic and possibilities for innovation in the local context. ${ }^{43}$ Involving co-researchers throughout the research process means not just encouraging participation at each stage, but respecting, valuing, acknowledging and incorporating community knowledge throughout. ${ }^{445}$ 
Table 5 Actions and tools/techniques to address power inequities in participatory health research

Aims

Actions
Tools/techniques that can support actions within research partnerships

Micro level

Embed discussions about power Be explicit and prioritise discussions about power and empowerment and empowerment within and beyond research partnerships

Demystify abstract concepts associated with 'power'

Explore power and empowerment terms and principles, strengthening understanding of concepts such as positionality and reflexivity and how they relate to power, privilege, and empowerment

Ensure power is considered and addressed throughout each stage of the research process

Jointly decide key stages in the research process where power will be explored, reviewed and reflected on (eg, at the start of the project, after data collection and analysis, during advocacy or when taking action, throughout dissemination)

Acknowledge deep-rooted Explore 'identity' within the research partnership, power dynamics and understand discussing how reflexivity, roles, responsibilities, what they mean for power sharing within research partnerships

\section{Strengthen capacity of}

community and academic partners to, individually and collectively, pursue co-produced knowledge and take action for sustainable impact on research aspirations and beyond language can support shifts in power

Embed, measure and monitor capacity

strengthening of soft and hard skills for community partners who are less experienced in research or social advocacy including confidence, selfesteem, effective leadership and communication, data collection and analysis, developing plans and constructing funding proposals knowledge exchange, capacity and choice of

- Explore assumptions about power using participatory tools such as Power Flower ${ }^{55}$, Chapati Diagram ${ }^{56}$ or Power Line ${ }^{61}$

- Rename and/or redefine CBPR principles so they are culturally appropriate, as done by the Nationa Black Leadership Initiative ${ }^{62}$

- Use metaphors, vignettes or alterative creative methods to demystify abstract concepts ${ }^{63}$

- Integrative practice framework that provides a structured process for developing and maintaining PR partnerships ${ }^{64}$

The Tree of Life ${ }^{65}$

River of Life ${ }^{66}$

- Metaphors to explore identity in relation to others $^{67}$

- Bilateral training for 'partnership readiness ${ }^{\prime 42} 68$

- Mentorships ${ }^{69}$

- Social advocacy training ${ }^{70}$

- Develop individual learning plans ${ }^{69}$

- Value Creation Stories that collectively and individually generate immediate, applied and potential value of learning activities ${ }^{71}$

\section{Meso level}

Enable community partners to set the agenda for the research and choose which approaches to implement

\section{Create safe communicative spaces for participants}

Minimise 'tokenistic' participation in research
Share knowledge of research methods,

interpretations, perceptions and interventions from similar projects in different contexts, promote and support community partner decision-making on which options to use or adapt

Conduct research activities and discussions in settings that are familiar to co-researchers and provide opportunities to share experiences in safe spaces (eg, some marginalised groups feel more comfortable sharing stories with others who have similar experiences)

Employ mechanisms that ensure alignment with participatory research principles for participatory research, ${ }^{39}$ employ community governance structures to serve as a source of accountability in the partnership and provide structure to guide the partnership's activities
- Ranking exercises ${ }^{72}$

- Participatory intervention mapping such as stepping stones to identify what steps are required to make change ${ }^{73}$

- Training to become a peer educator ${ }^{74}$

- Jointly develop ground rules for communicative spaces $^{75}$

- Ensure that there is collective voice to protect from the risks of individual representation ${ }^{76}$

- Assess who is present and the power dynamics that may be at play, considering intersection axis of inequities within group settings ${ }^{77}$.

- CBPR evaluation framework ${ }^{78}$

- Follow quality criteria for $\mathrm{PHR}^{79}$

- External and/or community advisory boards where community partners can voice concerns and priorities that otherwise might not enter into the researchers' agenda ${ }^{80}$
Protect communities from feeling coerced into participating in research

Shift decision-making to community partners early in the research process

Address hierarchies within and across stakeholder groups
Ensure safeguarding principles are in place within the research partnership and consider how opportunities to participate in research are presented and by whom

Generate governance processes that are documented, shared and agreed by all members that clearly indicate decision-making roles and mechanisms of consensus and conflict management

Co-develop indicators that can be used to jointly monitor shifts in the internal dynamics and relational environment within research partnerships
Guidance on Safeguarding in International Development Research ${ }^{81}$

- Memorandum of Understanding/Terms of Reference $^{82}$ Apply the 'Dimensions of structural governance' measures $^{83}$ 
Table 5 Continued

\begin{tabular}{|c|c|c|}
\hline Aims & Actions & $\begin{array}{l}\text { Tools/techniques that can support actions within } \\
\text { research partnerships }\end{array}$ \\
\hline $\begin{array}{l}\text { Maintain trust between different } \\
\text { stakeholder groups }\end{array}$ & $\begin{array}{l}\text { Manage expectations to balance research project } \\
\text { limitations and community needs/priorities while } \\
\text { supporting ideas and ways to expand beyond the } \\
\text { project scope }\end{array}$ & $\begin{array}{l}\text { Co-develop Terms of Reference to clearly define } \\
\text { and communicate project limitations } \\
\text { Conduct ranking exercises when multiple actions } \\
\text { Core suggested by communities }\end{array}$ \\
\hline $\begin{array}{l}\text { Ensure appropriate reward for } \\
\text { participation in research }\end{array}$ & $\begin{array}{l}\text { Discuss reward systems as a partnership, } \\
\text { explore what each partner wants to gain from the } \\
\text { collaboration, what would incentivise and motivate } \\
\text { them to continue, and what would be beneficial } \\
\text { to all }\end{array}$ & $\begin{array}{l}\text { Example incentives include monetary payment, } \\
\text { educational/training opportunities, prestige, } \\
\text { recognition in communities, becoming a peer } \\
\text { educator and increased access to information or } \\
\text { networks }\end{array}$ \\
\hline $\begin{array}{l}\text { Examine the ethical risks } \\
\text { associated with participatory } \\
\text { health research }\end{array}$ & $\begin{array}{l}\text { Have open transparent discussions that explore } \\
\text { the impact of empowerment on individuals and } \\
\text { groups within their sociopolitical environment }\end{array}$ & $\begin{array}{l}\text { Participatory Health Research: A Guide to Ethical } \\
\text { Principles and Practice } \\
\text { Model for developing context-sensitive responses } \\
\text { to vulnerability in research }\end{array}$ \\
\hline $\begin{array}{l}\text { Promote inclusivity and facilitate } \\
\text { mutual understanding }\end{array}$ & $\begin{array}{l}\text { Use participatory tools that promote inclusivity } \\
\text { such as creative and narrative techniques, drama, } \\
\text { storytelling, song and others }\end{array}$ & $\begin{array}{l}\text { Photovoice } \\
\text { Participatory video } \\
\text { Pigital storytelling } \\
\text { P8 } \\
\text { Participatory drawing } \\
\text { Participatory creative } \text { writing }^{90}\end{array}$ \\
\hline $\begin{array}{l}\text { Support documentation and } \\
\text { community ownership of local } \\
\text { knowledge }\end{array}$ & $\begin{array}{l}\text { Prioritise the documentation of community } \\
\text { knowledge that reflects local ways of knowing, } \\
\text { ensuring that legal frameworks are in place to } \\
\text { protect community rights and ownership of } \\
\text { outputs to prevent exploitation for the gains of } \\
\text { other more powerful partners }\end{array}$ & $\begin{array}{l}\text { Establish intellectual property rights, shared } \\
\text { authorship on publications, reports, blogs led } \\
\text { by community; see co-researcher blogs from } \\
\text { informal settlements in Bangladesh }\end{array}$ \\
\hline \multirow[t]{2}{*}{$\begin{array}{l}\text { Manage the balance of } \\
\text { gatekeeper involvement to } \\
\text { minimise potential exclusion of } \\
\text { the most marginalised }\end{array}$} & $\begin{array}{l}\text { Engage gatekeepers in attaining access to } \\
\text { communities early on in the research, }{ }^{52} \text { while } \\
\text { considering other avenues to work with diverse } \\
\text { population groups that may not be reached } \\
\text { through gatekeepers }\end{array}$ & $\begin{array}{l}\text { Stakeholder mapping }{ }^{92} \\
\text { Social network analysis } \\
\text { Social media analysis to identify supporting } \\
\text { groups }^{94}\end{array}$ \\
\hline & $\begin{array}{l}\text { Address ethical issues related to recruiting } \\
\text { participants through gatekeepers by examining the } \\
\text { complexities of human conduct }\end{array}$ & $\begin{array}{l}\text { Phronesis to support researchers to make } \\
\text { critical ethical decisions based on the specific } \\
\text { characteristics of the research sites and } \\
\text { subjects }^{95}\end{array}$ \\
\hline $\begin{array}{l}\text { Understand the motives and } \\
\text { intentions of gatekeepers }\end{array}$ & $\begin{array}{l}\text { Evaluate gatekeepers' motives, how routes of } \\
\text { access affect research participation, and how the } \\
\text { relationship between a gatekeeper and researcher } \\
\text { is established and maintained }\end{array}$ & $\begin{array}{l}\text { Establish trust and rapport with gatekeepers as } \\
\text { members in the research process - raising issues } \\
\text { of power and exclusion in research generally }{ }^{52}\end{array}$ \\
\hline \multicolumn{3}{|l|}{ Macro } \\
\hline $\begin{array}{l}\text { Ensure marginalised groups } \\
\text { have equal opportunities for } \\
\text { participation }\end{array}$ & $\begin{array}{l}\text { Undertake social mapping and discursive activities } \\
\text { to assess the distribution of power and resources } \\
\text { across population groups }\end{array}$ & $\begin{array}{l}\text { Governance diaries } \\
\text { Transect walks } \\
\text { Tr } \\
\text { Social mapping } \\
\text { Community dialogue } \\
\text { Cog }\end{array}$ \\
\hline $\begin{array}{l}\text { Recognise colonial legacies that } \\
\text { generate power inequities within } \\
\text { international partnerships }\end{array}$ & $\begin{array}{l}\text { Have open conversations on the place of the } \\
\text { 'foreign gaze', of local knowledge and of organic } \\
\text { change in global health to help identify strategies } \\
\text { to fundamentally undo colonial practices and } \\
\text { attitudes }^{100}\end{array}$ & $\begin{array}{l}\text { Authorial reflexivity matrix, with combinations of } \\
\text { local and foreign pose and gaze } e^{100}\end{array}$ \\
\hline
\end{tabular}

CBPR, community-based participatory research.

\section{Meso level}

At the meso level, key findings included the need to establish project governance processes that demarcate shared decision-making and power (including measures or indicators that can monitor shifts in power), to ensure alignment with participatory principles and avoid 'tokenistic' participation, to manage co-researcher expectations of the research process and to create spaces for trusted dialogue. Participants also discussed working with community advisory boards to increase accountability, co-developing reward systems that benefit all, safeguarding 'empowered community partners', protecting the intellectual rights of community knowledge and managing gatekeeper relations.

The complex and contested role of gatekeepers (eg, individuals/organisations that are important for community access but able to dictate who can participate) highlighted in our study is reflected and debated in the wider literature, ${ }^{546}$ and can be particularly problematic in terms of consent when gatekeepers are also service 
providers (eg, social services, health services). ${ }^{47}$ Even so, much of the literature agrees that gatekeeper endorsement is required, to an extent, in participatory research projects. ${ }^{48} 49$ Interestingly, few participants in this study discussed the more positive roles of gatekeeping, for example in protecting communities from exploitive, non-participatory or purely theoretical research ${ }^{50}$ or increasing solidarity in partnership building. ${ }^{51}$ McFadyen and Rankin $^{52}$ (p82) in their reflexive review of gatekeeper engagement in research found that the level of understanding about the research, communication issues, motivation issues and fear or anxiety about the outcome' were barriers to accessing marginalised groups. They also highlighted that when researching sensitive topics, gatekeepers should be engaged early in the research process to help manage attitudes and values that may be deeply held.

Participatory research exposes different safeguarding risks compared with traditional research approaches, and these risks should be explored in-depth and navigated to protect co-researchers and communities from harm. It is also important to ensure that safeguarding choices are co-developed and not imposed by academic 'outsider' researchers or research ethics boards from different sociodemographic and geographical contexts. ${ }^{53}{ }^{54}$ Likewise, workshop participants reinforced the importance of creating safe communicative spaces as part of the trust-building process, which other studies have called out, ${ }^{55}$ especially when working with marginalised groups or those who have had negative research experiences. ${ }^{56}$

\section{Macro level}

At the macro level, participatory researchers reflected on the larger dynamics of discrimination and exclusion that impact PHR, the legacy of traditional research approaches, the unequal distribution of resources which can affect participation and the political and legal contexts that can put participants at risk of harm because of their participation.

Decolonisation has become a pressing topic in global health research in recent years. ${ }^{57}$ Participants in this study were aware of the realities of historical and contemporary power structures and the ways in which these structures continue to impact research processes. For example, participants discussed the legacy of traditional research approaches which have damaged trust between researchers and communities. Sometimes termed 'extractive' research, ${ }^{58}$ these approaches have left communities feeling that they should be passive subjects in research, or that they need to be 'instructed' on how to do research, thereby reducing community receptivity to more participatory ways of working. Historically marginalised communities often have greater research weariness as they are more likely to have been exploited or mistreated by researchers or medical professionals in the past. ${ }^{59}$

\section{Strengths and limitations}

The strength of this research lies in the drawing together of diverse views on power from people working in different spaces across different disciplines. We engaged with researchers who had participatory research experience working in 24 different countries, 20 of which are in the Global South. Their perspectives contribute to the creation of diverse knowledge systems on power. By emphasising a methodology developed in the Global South, and prioritising local and diverse knowledge, participatory research can help catalyse the shifts in global health research that are called for in the movement to decolonise global health. ${ }^{60}$ This study, presenting a wide range of insights related to power sharing in participatory and co-production research, is therefore timely, and will help to advance the practice of co-production research.

One of the main weaknesses of this study was the lack of engagement of community co-researchers and other nonacademic or professional stakeholders. We identified and discussed potential barriers to community co-researcher participation in Egid et al 2021, ${ }^{34}$ which included limited access to the online platform, COVID-19 restrictions that made it difficult to access the Internet from shared spaces, issues with recruitment, language barriers, and power imbalances within the workshops. The absence of community co-researchers in the participant group may have acted to reinforce existing power differentials between academic and community co-researchers, as the study effectively gave a voice to the those who already held more 'privileged' power and overlooked the fact that community co-researchers have distinct experiences of power. ${ }^{19}$ Engaging community-based co-researchers and other non-academic stakeholders in future research of this type will be essential for ensuring that new understandings of power in PHR are representative of all stakeholders engaged in participatory processes.

\section{CONCLUSIONS}

Despite widespread assumptions about power sharing and trust-building dynamics, adopting a participatory approach is not in itself sufficient for addressing power inequities. The 'Social Ecology of Power' framework is a useful tool for engaging with power inequities that cut across the social ecology, highlighting how they can operate at the micro (individual), meso (interpersonal) and macro (structural) level. These inequities must be identified, discussed and addressed throughout the research process. This study reiterates that power is pervasive, and that while many researchers are intentional about engaging with power, actions and available tools must be used more systematically to identify and address power imbalances in co-production and participatory research partnerships, in order to contribute to improved equity and social justice outcomes.

\footnotetext{
Author affiliations

${ }^{1}$ Department of Vector Biology, Liverpool School of Tropical Medicine, Liverpool, UK

${ }^{2}$ School of Public Health, University College Cork, Cork, Ireland

${ }^{3}$ James P Grant School of Public Health, BRAC University, Dhaka, Bangladesh
} 
${ }^{4}$ Department of International Public Health, Liverpool School of Tropical Medicine, Liverpool, UK

${ }^{5}$ Urbanisation and Wellbeing Unit, African Population and Health Research Center, Nairobi, Kenya

${ }^{6}$ NOVA National School of Public Health, Public Health Research Centre, Universidade Nova de Lisboa and Comprehensive Health Research Centre, Lisboa, Portugal

7INCAP Research Center for Prevention of Chronic Diseases, Institute of Nutrition of Central America and Panama, Guatemala City, Guatemala

${ }^{8}$ School of Medicine, University of Maryland, Baltimore, Maryland, USA

${ }^{9}$ Department of Research and Strategic Information, LVCT Health, Nairobi, Kenya

${ }^{10}$ Department of Community Medicine, University of Jos, Jos, Nigeria

${ }^{11}$ Parul Institute of Public Health, Faculty of Medicine, Parul University, Vadodara, Gujarat, India

${ }^{12}$ Independent Researcher, Baltimore, Maryland, USA

${ }^{13}$ School of Community Health and Policy, Prevention Sciences Research Center,

Morgan State University, Baltimore, Maryland, USA

${ }^{14}$ Center for Participatory Research, College of Population Health, University of New Mexico, Albuquerque, New Mexico, USA

${ }^{15}$ Center on Society and Health, Virginia Commonwealth University, Richmond, Virginia, USA

Twitter Beatrice R Egid @beatrice_egid, Bachera Aktar @AktarBachera, Ivy Chumo @chumo_ivy, Luret Lar @DrLuretLar, Yaimie López @yaimie_lopez91, Apurvakumar Pandya @apurva_b_pandya and Kim Ozano @Kim_Ozano

Contributors BRE, MR, SD, GH, LJ, YL, PS, NW, EZ and KO conceptualised the study and designed the workshop questions and format. BRE, MR, GH, LJ, PS and $\mathrm{KO}$ facilitated the workshops. BRE, EZ and KO conducted the analysis and BRE wrote the first draft of the manuscript. MR, SD, LJ, YL, PS, NW, EZ and KO critically reviewed and modified the initial and subsequent drafts. BA, JAQ, IC, RK, LL, AP, TCN and TT contributed to co-production of data in the workshops and reviewed and provided feedback on draft manuscripts. KO is the guarantor for this study.

Funding This research was supported through the GCRF Accountability for Informal Urban Equity Hub (ARISE), a UKRI Collective Fund award with reference ES/S00811X/1, and The COUNTDOWN programme, funded by UKAID, part of the Foreign, Commonwealth and Development Office (FCDO) with award reference P0 6407.

\section{Competing interests None declared.}

Patient and public involvement Patients and/or the public were not involved in the design, or conduct, or reporting, or dissemination plans of this research.

Patient consent for publication Not applicable.

Ethics approval This study received approval from the Research Ethics Committee at the Liverpool School of Tropical Medicine, Liverpool, UK (20-041) in May 2020.

Provenance and peer review Not commissioned; externally peer reviewed.

Data availability statement Data are available upon reasonable request.

Open access This is an open access article distributed in accordance with the Creative Commons Attribution Non Commercial (CC BY-NC 4.0) license, which permits others to distribute, remix, adapt, build upon this work non-commercially, and license their derivative works on different terms, provided the original work is properly cited, appropriate credit is given, any changes made indicated, and the use is non-commercial. See: http://creativecommons.org/licenses/by-nc/4.0/.

ORCID iD

Beatrice R Egid http://orcid.org/0000-0001-8206-8903

\section{REFERENCES}

1 ICPHR. Position paper 3: Impact in participatory health research. Berlin: International Collaboration for Participatory Health Research, 2020.

2 Agyepong IA, Godt S, Sombie I, et al. Strengthening capacities and resource allocation for co-production of health research in low and middle income countries. BMJ 2021;372:n166.

3 Redman S, Greenhalgh T, Adedokun L, et al. Co-production of knowledge: the future. BMJ 2021;372:n434.

4 Bradshaw TK. The Post-place community: contributions to the debate about the definition of community. Community Development 2008;39:5-16.
5 Rose D. Participatory research: real or imagined. Soc Psychiatry Psychiatr Epidemiol 2018;53:765-71.

6 Roura M. The social ecology of power in participatory health research. Qual Health Res 2021;31:778-88.

7 Cooke B, Kothari U. Participation: the new tyranny? London: Zed Books Ltd, 2001

8 Wallerstein N, Duran B. Community-Based participatory research contributions to intervention research: the intersection of science and practice to improve health equity. Am J Public Health 2010;100 Suppl 1:S40-6.

9 Tucker CM, Williams JL, Roncoroni J, et al. A socially just leadership approach to community-partnered research for reducing health disparities. Couns Psychol 2017;45:781-809.

10 Rawson TM, Castro-Sánchez E, Charani E, et al. Involving citizens in priority setting for public health research: implementation in infection research. Health Expect 2018;21:222-9.

11 Cornwall A. Unpacking 'participation': models, meanings and practices. Community Dev J 2008;43:269-83.

12 Skewes MC, Gonzalez VM, Gameon JA, et al. Health disparities research with American Indian communities: The importance of trust and transparency. Am J Community Psychol 2020;66:302-13.

13 Brandt AM. Racism and research: the case of the tuskegee syphilis study. Hastings center report, 1978: 21-9.

14 Cunningham JK, Solomon TA, Muramoto ML. Alcohol use among Native Americans compared to whites: Examining the veracity of the 'Native American elevated alcohol consumption' belief. Drug Alcohol Depend 2016;160:65-75.

15 Courtenay-Quirk C, Wolitski RJ, Parsons JT, et al. Is HIV/AIDS stigma dividing the gay community? perceptions of HIV-positive men who have sex with men. AIDS Educ Prev 2006;18:56-67.

16 Dadich A, Moore L, Eapen V. What does it mean to conduct participatory research with Indigenous peoples? A lexical review. BMC Public Health 2019;19:1388.

17 Freudenberg N, Tsui E. Evidence, power, and policy change in community-based participatory research. Am J Public Health 2014;104:11-14.

18 Avelino F, Rotmans J. Power in transition: an interdisciplinary framework to study power in relation to structural change. European Journal of Social Theory 2009;12:543-69.

19 Wallerstein N, Muhammad M, Sanchez-Youngman S, et al. Power dynamics in community-based participatory research: a multiplecase study analysis of partnering contexts, histories, and practices. Health Educ Behav 2019;46:19S-32.

20 Devia C, Baker EA, Sanchez-Youngman S, et al. Advancing system and policy changes for social and racial justice: comparing a rural and urban community-based participatory research partnership in the U.S. Int J Equity Health 2017;16:1-14.

21 Ward M, Schulz AJ, Israel BA, et al. A conceptual framework for evaluating health equity promotion within communitybased participatory research partnerships. Eval Program Plann 2018;70:25-34.

22 Minkler Met al. Community-based participatory research: A strategy for building healthy communities and promoting health through policy change. PolicyLink: Oakland, 2012.

23 Suarez-Balcazar Y, Francisco VT, Rubén Chávez N. Applying community-based participatory approaches to addressing health disparities and promoting health equity. Am J Community Psychol 2020;66:217-21.

24 McLaren L, Hawe P. Ecological perspectives in health research. $J$ Epidemiol Community Health 2005;59:6-14.

25 Gaventa J, Cornwall A. Power and Knowledge. In: Reason,P, Bradbury $\mathrm{H}$, eds. The SAGE Handbook of action research. 3rd edn. CA: Sage, 2015.

26 Ford C, Griffith M, Bruce M, et al. Racism: science and tools for the public health professional. American Public Health Association Press, 2019.

27 Wallerstein N, Duran B. Historical, theoretical and practice roots of CBPR. In: Wallerstein N, Duran B, Oetzel J, et al, eds. CommunityBased participatory research for health: advancing social and health equity. San Francisco: Jossey-Bass, 2017.

28 Jagosh J, Bush PL, Salsberg J, et al. A realist evaluation of community-based participatory research: partnership synergy, trust building and related ripple effects. BMC Public Health 2015;15:725.

29 Adib Hagbaghery M, Salsali M, Ahmadi F. A qualitative study of Iranian nurses' understanding and experiences of professional power. Hum Resour Health 2004;2:9.

30 Verbeke E, Vanheule S, Cauwe J, et al. Coercion and power in psychiatry: a qualitative study with ex-patients. Soc Sci Med 2019;223:89-96.

31 Openjuru GLet al. Despite knowledge democracy and communitybased participatory action research: voices from the global south 
and excluded north still missing. SAGE Publications Sage UK: London, England, 2015.

32 Abimbola S. The uses of knowledge in global health. BMJ Glob Health 2021;6:e005802.

33 Caretta MA, Vacchelli E. Re-thinking the boundaries of the focus group: a reflexive analysis on the use and legitimacy of group methodologies in qualitative research. Sociol Res Online 2015;20:58-70.

34 Egid B, Ozano K, Hegel G, et al. Can everyone hear me? reflections on the use of global online workshops for promoting inclusive knowledge generation. Qualitative Research 2021;10:146879412110195.

35 Johnson TP. Snowball sampling: introduction. Wiley StatsRef: Statistics Reference Online, 2014.

36 Furber C. Framework analysis: a method for analysing qualitative data. Afr J Midwifery Womens Health 2010;4:97-100.

37 Groot BC, Abma TA. Participatory health research with older people in the Netherlands: navigating power imbalances towards mutually transforming power, in participatory health research. Springer, 2018: 165-78.

38 George AS, Mehra V, Scott K, et al. Community participation in health systems research: a systematic review assessing the state of research, the nature of interventions involved and the features of engagement with communities. PLoS One 2015;10:e0141091.

39 Israel BA, Schulz AJ, Parker EA, et al. Review of community-based research: assessing partnership approaches to improve public health. Annu Rev Public Health 1998;19:173-202.

40 Healy K. Participatory action research and social work: a critical appraisal. International Social Work 2001;44:93-105.

41 Reid DG, Mair H, Taylor J. Community participation in rural tourism development. World Leis J 2000;42:20-7.

42 Andrews JO, Newman SD, Meadows O, et al. Partnership readiness for community-based participatory research. Health Educ Res 2012;27:555-71.

43 Crisp N. Mutual learning and reverse innovation--where next? Global Health 2014;10:14.

44 Esler DM. Participatory action research in Indigenous health. Aust Fam Physician 2008;37:457.

45 Dias S, Gama A, Simões D, et al. Implementation process and impacts of a participatory HIV research project with key populations. Biomed Res Int 2018;2018:1-9.

46 Chabot C, Shoveller JA, Spencer G, et al. Ethical and epistemological insights: a case study of participatory action research with young people. J Empir Res Hum Res Ethics 2012;7:20-33.

47 Molyneux CS, Wassenaar DR, Peshu N, et al. 'Even if they ask you to stand by a tree all day, you will have to do it (laughter)...!': community voices on the notion and practice of informed consent for biomedical research in developing countries. Soc Sci Med 2005;61:443-54

48 Pinto RM, Schmidt CNT, Rodriguez PSO, et al. Using principles of community participatory research Groundwork for a collaboration in Brazil. Int Soc Work 2007;50:53-65.

49 Lo B, Bayer R. Establishing ethical trials for treatment and prevention of AIDS in developing countries. BMJ 2003;327:337-9.

50 Mosavel M, Simon C, van Stade D, et al. Community-Based participatory research (CBPR) in South Africa: engaging multiple constituents to shape the research question. Soc Sci Med 2005;61:2577-87.

51 Lowan-Trudeau G. Gatekeeper or gardener? exploring positioning, paradigms, and metaphors in Indigenous environmental education research. J Environ Educ 2019;50:348-57.

52 McFadyen J, Rankin J. The role of gatekeepers in research: learning from reflexivity and reflection. GSTF Journal of Nursing and Health Care 2016;4.

53 Banks Set al. Participatory health research: a guide to ethical principles and practice. Berlin, 2013.

54 Aktar B, Alam W, Ali S, et al. How to prevent and address Safeguarding concerns in global health research programmes: practice, process and positionality in marginalised spaces. BMJ Glob Health 2020;5:e002253.

55 LGBTQ2S_Toolkit. Power flower. Available: http://lgbtq2stoolkit. learningcommunity.ca/training/power-flower/ [Accessed $16 \mathrm{Jul}$ 2021].

56 Reflection_Action. Chapatti diagram - spaces of power. Available: https://www.reflectionaction.org/tools_and_methods/59/ [Accessed 19 Jul 2021].

57 Büyüm AM, Kenney C, Koris A, et al. Decolonising global health: if not now, when? BMJ Glob Health 2020;5:e003394.

58 Gaudry AJP. Insurgent research. Wicazo Sa Review 2011;26:113-36.
59 Danquah S, Billingham L. Community research: moving from exploitative extraction to genuine collaboration. TSIP, 2020.

60 Khan M, Abimbola S, Aloudat T, et al. Decolonising global health in 2021: a roadmap to move from rhetoric to reform. BMJ Glob Health 2021;6:e005604

61 Power line. Available: https://www.reflectionaction.org/tools_and methods/28/?from=ov [Accessed 01 Oct 2021].

62 Smith SA, Whitehead MS, Sheats JQ, et al. Community-based participatory research principles for the African American community. J Ga Public Health Assoc 2015;5:52.

63 Canfield C, Angove R, Boselovic J, et al. Developing a communitybased participatory research curriculum to support environmental health research partnerships: an initiative of the GROWH community outreach and dissemination core. Int $J$ Nurs Clin Pract 2016;3. doi:10.15344/2394-4978/2016/187. [Epub ahead of print: 3006 2016]

64 Cargo M, Mercer SL. The value and challenges of participatory research: strengthening its practice. Annu Rev Public Health 2008;29:325-50.

65 Weller NB. The tree of life: a simple exercise for reclaiming your identity and direction in life through story, 2014.

66 Sanchez-Youngman S, Wallerstein N. Partnership river of Life: creating a historical time line. In: Wallerstein N, Duran B, Oetzel JG, et al, eds. Community-based participatory research for health: advancing social and health equity. San Francisco: Jossey-Bass, 2018: 375-8.

67 Kramer-Roy D. Using participatory and creative methods to facilitate emancipatory research with people facing multiple disadvantage: a role for health and care professionals. Disabil Soc 2015;30:1207-24.

68 Andrews JO, Cox MJ, Newman SD, et al. Development and evaluation of a toolkit to assess partnership readiness for community-based participatory research. Prog Community Health Partnersh 2011;5:183-8.

69 Masuda JR, Creighton G, Nixon S, et al. Building capacity for community-based participatory research for health disparities in Canada: the case of "partnerships in community health research". Health Promot Pract 2011;12:280-92.

70 Tremblay M-C, Martin DH, McComber AM, et al. Understanding community-based participatory research through a social movement framework: a case study of the kahnawake schools diabetes prevention project. BMC Public Health 2018;18:487.

71 Wenger E, Trayner B, De Laat M. Promoting and assessing value creation in communities and networks: a conceptual framework, 2011.

72 Ager A, Sparling T. Participatory ranking methodology: a brief guide. Columbia University Mailman School of Public Health, 2013.

73 Fapohunda VOet al. Stepping stones method: a participatory research method to understand health care pathways for female genital schistosomiasis in Nigeria, 2020.

74 Wawrzynski MR, Lemon JD. Trends in health and wellness peer educator training: a five-year analysis. J Stud Aff Res Pract 2021;58:135-47.

75 Lolacono Merves M, Rodgers CRR, Silver EJ, et al. Engaging and sustaining adolescents in community-based participatory research: structuring a youth-friendly community-based participatory research environment. Fam Community Health 2015;38:22-32.

76 Williamson KM, Brown K. Collective voices: engagement of Hartford community residents through participatory action research. Qualitative Report 2014;19.

77 Ozano K, Khatri R. Reflexivity, positionality and power in crosscultural participatory action research with research assistants in rural Cambodia. Educ Action Res 2018;26:190-204.

78 Belone L, Lucero JE, Duran B, et al. Community-based participatory research conceptual model: Community partner consultation and face validity. Qual Health Res 2016;26:117-35.

79 Springett J, Wright MT, Roche B. Developing quality criteria for participatory health research: an agenda for action. WZB Discussion Paper, 2011.

80 Newman SD, Andrews JO, Magwood GS, et al. Community Advisory boards in community-based participatory research: a synthesis of best processes. Prev Chronic Dis 2011;8:A70

81 (UKCDR), U.C.o.D.R. Guidance on Safeguarding in internationa development research. Available: https://www.ukcdr.org.uk/ wp-content/uploads/2020/04/170420-UKCDR-Guidance-forSafeguarding-in-International-Development-Research.pdf [Accessed 29 Sep 2021].

82 Gehlert S, Fayanju OM, Jackson S, et al. A method for achieving reciprocity of funding in community-based participatory research. Prog Community Health Partnersh 2014;8:561-70. 
83 Sanchez-Youngman S, Boursaw B, Oetzel J, et al. Structural community governance: importance for CommunityAcademic research partnerships. Am J Community Psychol 2021;67:271-83.

84 Ortiz O, Orrego R, Pradel W, et al. Incentives and disincentives for stakeholder involvement in participatory research (PR): lessons from potato-related PR from Bolivia, Ethiopia, Peru and Uganda. Int $J$ Agric Sustain 2011;9:522-36.

85 Molyneux S, Sukhtankar P, Thitiri J, et al. Model for developing context-sensitive responses to vulnerability in research: managing ethical dilemmas faced by frontline research staff in Kenya. BMJ Glob Health 2021;6:e004937.

86 Wang C, Burris MA. Photovoice: concept, methodology, and use for participatory needs assessment. Health Educ Behav 1997;24:369-87.

87 Tauschinski J. What is participatory video? 2019. Available: https:// www.youngfoundation.org/research/what-is-participatory-video/ [Accessed 01 Oct 2021].

88 de Jager Aet al. Digital Storytelling in research: a systematic review. Qual Rep 2017;22.

89 Literat I. "A pencil for your thoughts": participatory drawing as a visual research method with children and youth. Int J Qual Methods 2013;12:84-98

90 Bundesen B, Aymo-Boot M, Djørup A, et al. REWRITALIZE: participatory creative writing groups led by authors in collaboration with mental health care professionals for people experiencing severe mental illness. Nordic Journal of Arts, Culture and Health 2020;2:140-7.

91 ARISE. Supporting communities in the COVID-19 pandemic: ARISE community researcher experiences, 2021.

92 Murray-Webster R, Simon P. Making sense of stakeholder mapping. PM World today 2006;8:1-5.

93 Ekirapa-Kiracho E, Ghosh U, Brahmachari R, et al. Engaging stakeholders: lessons from the use of participatory tools for improving maternal and child care health services. Health Res Policy Syst 2017:15:106.

94 Lai LS, To WM. Content analysis of social media: a grounded theory approach. Journal of Electronic Commerce Research 2015;16:138.

95 McAreavey R, Das C. A delicate balancing act: negotiating with gatekeepers for ethical research when researching minority communities. Int J Qual Methods 2013;12:113-31.

96 Loureiro Met al. Governance diaries: an approach to governance research from the ground up. IDS, 2020.

97 Rojas A, Nomedji K, West CT. Walking the line: conducting transect walks in Burkina Faso. Pract Anthropol 2021;43:18-21.

98 Emmel N. Participatory mapping: an innovative sociological method, 2008.

99 Woolrych R, Gibson N, Sixsmith J, et al. "No home, no place": addressing the complexity of homelessness in old age through community dialogue. J Hous Elderly 2015;29:233-58.

100 Abimbola S. The foreign gaze: authorship in academic global health. BMJ Glob Health 2019;4:e002068. 